MATEC Web of Conferences 31, 07001 (2015)

DOI: $10.1051 /$ matecconf/ 20153107001

(C) Owned by the authors, published by EDP Sciences, 2015

\title{
Sensorless Control Technology for PMSG base on the Dead-time Compensation voltage
}

\author{
Yang Li-yong ${ }^{1}$, Zhai Fei ${ }^{2, a}$ \\ 1 North China University of Technology, China \\ ${ }^{2}$ North China University of Technology, China
}

\begin{abstract}
In order to improve the speed sensorless-control system of PMSG in low speed performance, this paper introduces a novel Dead-time compensation control method .Mathematical model is established according to the Dead-zone of the influence of the voltage source type inverter output voltage. At the same time, the given value of current regulator output voltage has been fixed based on the established model. Then the stator voltage after compensationed is applied to the flux estimation, which improves the performance of flux estimation. Finally, the position and speed of the rotor is estimated based on Back-Electromotive Force, which has Simple algorithm and good robustness. In order to verify the correctness of theoretical analysis, the experiment was done according to the new control method. The results proved the correctness and feasibility of this control method.
\end{abstract}

Key Words: Permanent Magnet Synchronous wind power Generator; Back Electromotive Force; Dead-time voltage Compensation; Flux Estimate

\section{Introduction}

Wind energy is widely seen as a substitute for the traditional non renewable energy due to its large-scale development and utilization and no pollution. Permanent magnet synchronous wind power generator has a wide application prospect, because of its compact structure, reliable performance and excellent power system fault adaptive [1-3].Sensorless control technology is to estimate the rotor position and speed by a specific algorithm, related to the use of easily measured variables which is in the motor winding, such as the stator voltage, stator current, winding flux. The purpose is to realize the high precision control of permanent magnet motor [4].A series of problems existing in mechanical sensor can be solved by using the speed sensorless technology. So that the reliability of the system is improved, the cost is reduced greatly [5].

In the speed sensorless permanent magnet synchronous wind generator control system, flux estimation requires stator voltage. If a given voltage in the SVPWM algorithm is used as electronic voltage. It will cause error about the flux estimation and reduce the flux estimation accuracy. Finally it have a serious impact on the performance of low-speed permanent magnet motor, because the dead time effect [6].

The Back-EMF method is widely used, because of its physical concept is clear, small amount of calculation [7]. The combination of Back-EMF and dead voltage compensation is achieved the precise control of the sensorless permanent magnet synchronous generator. In this paper, a method is introduced about the sensorless permanent magnet

\footnotetext{
${ }^{a}$ Corresponding author:zhaifei523@163.com
} 
synchronous wind generator control system.First of all, the inverter output voltage distortion is compensated, by the detection of three-phase voltage and three-phase current in the system. Then, according to the motor model, we calculated the rotor position deviation of motor and used Back-EMF method to track estimation of rotor position. Finally, the theory is verified by hardware experiment platform based on TMS320F28335 control panel.

\section{Modeling for PMSG}

\subsection{A mathematical model of Back-EMF method}

\section{PMSG}

Mathematical model is an important means to study the actual physical object. In order to analyze and control of PMSG, the establishment of mathematical model with simple and feasible is very necessary.

There are two kinds of coordinates in the generator vector control system of permanent magnet synchronous wind. One is two-phase rotating coordinate system ( $\mathrm{d}-\mathrm{q}$ coordinate) and the other is two-phase stationary coordinate system (alpha-beta coordinate system).In order to calculate the rotor position, We have to get the value of the stator flux linkage. A simple method of estimating the stator flux is the voltage model of stator flux in the alpha beta coordinate system and it is also the basis of other flux estimation method. This method only requires the use of a stator resistance parameter. So it is easy to be realized and has better robustness. When the power supply frequency is high, this estimation method has better estimation accuracy especially.

In alpha-beta coordinate system, vector induced electromotive force is defined as

$$
e_{s}=u_{s}-R_{s} i_{s}
$$

The relationship between the stator flux vector and induced electromotive force vectoris

$$
\frac{d \psi_{s}}{d t}=e_{s}=u_{s}-R_{s} i_{s}
$$

The equation(2)on both sides of integral

$$
\psi_{s}=\int e_{s} d t=\int\left(u_{s}-R_{s} i_{s}\right) d t
$$

Type(3)in the form of a component

$$
\left\{\begin{array}{l}
\psi_{s \alpha}=\int e_{s \alpha} d t=\int\left(u_{s \alpha}-R_{s} i_{s \alpha}\right) d t \\
\psi_{s \beta}=\int e_{s \beta} d t=\int\left(u_{s \beta}-R_{s} i_{s \beta}\right) d t
\end{array}\right.
$$

The calculation process of stator flux using the formula(4)need use not only the stator current signal, but also the stator voltage signal. So the formula(4)is called the voltage model in alpha beta coordinate of stator flux linkage. In the process of flux estimation, the estimation accuracy of the voltage model may be affected by the pure integrator. This is due to the voltage and current signal of $D C$ component and the initial error and especially when the motor is in low frequency, this kind of influence is more serious.

In order to solve this problem, a low pass filter is introduced to replace the pure integral of basic voltage model.

The transfer function of the lowpass filter is $G_{L P}(s)=\frac{1}{s+\omega_{c}}$. where $\omega_{c}$ is the cutoff frequency of the lowpass filter.

According to equation(4)can be obtained for the stator flux estimator based on the low-pass filter.

$$
\left\{\begin{array}{l}
\psi_{s \alpha}(s)=\frac{1}{s+\omega_{c}} e_{s \alpha}(s)=\frac{1}{s+\omega_{c}}\left[u_{s \alpha}(s)-R_{s} i_{s \alpha}(s)\right] \\
\psi_{s \beta}(s)=\frac{1}{s+\omega_{c}} e_{s \beta}(s)=\frac{1}{s+\omega_{c}}\left[u_{s \beta}(s)-R_{s} i_{s \beta}(s)\right]
\end{array}\right.
$$

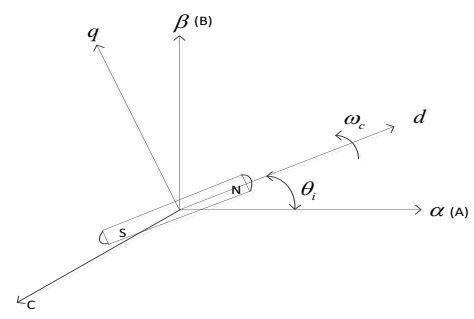

Fig.1 The relationship between the coordinate system PMSG 
According to the Fig.1, the rotor position of $P M S G$ can be expressed as [8]

$$
\theta_{i}=\arctan \left(\frac{\psi_{s \beta}}{\psi_{s \alpha}}\right)
$$

Because the Back-EMF $e_{s}$ can be divided into type

$$
e_{s}=\left[\begin{array}{c}
e_{s \alpha} \\
e_{s \beta}
\end{array}\right]=\left[\begin{array}{c}
-\psi_{f} \omega_{c} \sin \theta \\
\psi_{f} \omega_{c} \cos \theta
\end{array}\right]
$$

Where $\psi_{f}$ is rotor flux, $e_{s \alpha}$ and $e_{s \beta}$ is the Back-EMF of the alpha beta coordinate axis component.

Therefore the motor speed is expressed as according to the equation (7)

$$
\omega_{c}=\sqrt{e_{s \alpha}^{2}+e_{s \beta}^{2}} / \psi_{f}
$$

\subsection{The mathematical model of the inverter output}

\section{voltage}

In the Back-EMF method, the inverter output voltage value is used as the system state variables, but due to the influence of DTCV, the actual output voltage distortion, eventually lead to serious deviation of the estimated angle[9].

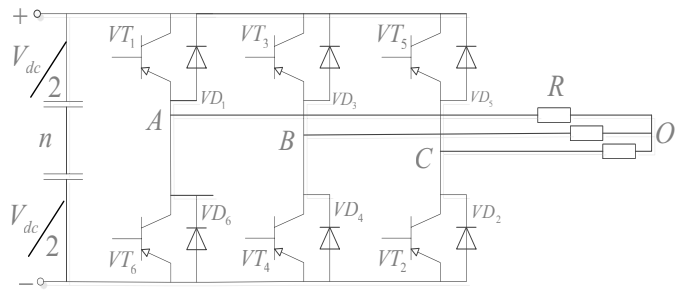

Fig.2 Three phase bridge inverter main circuit diagram

Power device VT1-VT6 can be controlled on and off by various methods, $V D 1-V D 6$ is free wheeling diode. $V_{d c}$ is the $D C$ bus voltage, $\mathrm{n}$ is a $D C$ link neutral point potential, $O$ motor winding neutral point.

Therefore, relative to the neutral point $O$ of the motor, $A, B, C$ three points voltage and current equations respectively

$$
\begin{gathered}
\left\{\begin{array}{l}
V_{A n}=V_{A O}+V_{n O} \\
V_{B n}=V_{B O}+V_{n O} \\
V_{C n}=V_{C O}+V_{n O}
\end{array}\right. \\
\left\{\begin{array}{c}
i_{A}+i_{B}+i_{C}=0 \\
V_{A n}+V_{B n}+V_{C n}=0
\end{array}\right. \\
V_{\mathrm{n} O}=-\frac{1}{3}\left(V_{A \mathrm{n}}+V_{B \mathrm{n}}+V_{C \mathrm{n}}\right)
\end{gathered}
$$

Because of the uncertainty caused by the current direction, the actual phase voltage of $A, B, C$ three-phase is difficult to estimate.

Assuming the direction of the current does not change in a switching period, the actual voltage of $A$ phase is expressed as follows, relative to the midpoint of the busbar $O$.

$$
\begin{gathered}
v_{A o}=\left(V_{d c}-V_{c e}+V_{d}\right)\left(S_{A}-0.5\right)- \\
0.5 \operatorname{sign}\left(i_{A}\right)\left(V_{c e}+V_{d}\right)
\end{gathered}
$$

In the formula, $\mathrm{Vdc}$ is the $D C$ busbar voltage of inverter, Vce is the tube voltage drop of power devices, $\mathrm{Vd}$ is the tube voltage drop of fly-wheel diode. $S_{A}=1$ represents the high level of the $A$ phase of the drive pulse and $S_{A}=0$ represents the low level of the $A$ phase of the drive pulse.

Because $V_{c e}$ and $V_{d}$ is increased with the rise of the current, effect of time of $S_{A}=1$ state for $T_{a}$, effect of time of $S_{A}=0$ state for $T_{s}-T_{a}$.

In one switching period, put $V_{c e}=V_{c e 0}+R_{c e}\left|i_{A}\right|$ 、 $V_{d}=V_{d 0}+R_{d}\left|i_{A}\right| \quad$ and $\quad s_{A}=\frac{T_{a}}{T_{s}} \quad$ into the formula (12),the average voltage can be expressed as

$$
\begin{aligned}
v_{A O}= & \left(V_{d c}-V_{c e}+V_{d}\right)\left(\frac{T_{a}}{T_{S}}-0.5\right)-0.5 \operatorname{sign}\left(i_{A}\right)\left(V_{c e 0}+V_{d 0}\right)- \\
& 0.5\left(R_{c e}+R_{d}\right) i_{A}
\end{aligned}
$$

Where $\operatorname{sign}\left(i_{A}\right)=\left\{\begin{array}{c}1, i_{A}>0 \\ -1, i_{A}<0\end{array}, i_{a .}>0\right.$ represent the current from the inverter to motor.

Therefore, $V_{A O}$ has moved with the switch state and the current direction[10].

Similarly, $B$ and $C$ phase voltage can be expressed as: 


$$
\begin{aligned}
v_{B O}= & \left(V_{d c}-V_{c e}+V_{d}\right)\left(\frac{T_{b}}{T_{S}}-0.5\right)-0.5 \operatorname{sign}\left(i_{B}\right)\left(V_{c e 0}+V_{d 0}\right)- \\
& 0.5\left(R_{c e}+R_{d}\right) i_{B} \\
v_{C O}= & \left(V_{d c}-V_{c e}+V_{d}\right)\left(\frac{T_{c}}{T_{S}}-0.5\right)-0.5 \operatorname{sign}\left(i_{C}\right)\left(V_{c e 0}+V_{d 0}\right)- \\
& 0.5\left(R_{c e}+R_{d}\right) i_{C}
\end{aligned}
$$

Type (9) (11) into the formula (13) (15) can be obtained:

$$
\begin{aligned}
v_{A n}= & \frac{1}{3}\left(V_{d c}-V_{c e}+V_{d}\right)\left(\frac{2 T_{a}-T_{b}-T_{c}}{T_{S}}\right)- \\
& \frac{V_{c e 0}+V_{d 0}}{6}\left[2 \operatorname{sign}\left(i_{A}\right)-\operatorname{sign}\left(i_{B}\right)-\operatorname{sign}\left(i_{C}\right)\right] \\
& -0.5\left(R_{c e}+R_{d}\right) i_{A} \\
v_{B n}= & \frac{1}{3}\left(V_{d c}-V_{c e}+V_{d}\right)\left(\frac{2 T_{c}-T_{b}-T_{a}}{T_{S}}\right)- \\
& \frac{V_{c e 0}+V_{d 0}}{6}\left[2 \operatorname{sign}\left(i_{B}\right)-\operatorname{sign}\left(i_{A}\right)-\operatorname{sign}\left(i_{C}\right)\right] \\
& -0.5\left(R_{c e}+R_{d}\right) i_{B} \\
v_{C n} & =\frac{1}{3}\left(V_{d c}-V_{c e}+V_{d}\right)\left(\frac{2 T_{c}-T_{b}-T_{a}}{T_{S}}\right)- \\
& \frac{V_{c e 0}+V_{d 0}}{6}\left[2 \operatorname{sign}\left(i_{C}\right)-\operatorname{sign}\left(i_{B}\right)-\operatorname{sign}\left(i_{A}\right)\right] \\
& -0.5\left(R_{c e}+R_{d}\right) i_{C}
\end{aligned}
$$

The above formula can be simplified as:

$$
\begin{gathered}
\left\{\begin{array}{l}
V_{A O}=V_{A n}-V_{n O}=V_{A O}^{*}+V_{A O}^{\prime}-\frac{1}{2}\left(R_{c e}+R_{d}\right) i_{A} \\
V_{B O}=V_{B n}-V_{n O}=V_{B O}^{*}+V_{B O}^{\prime}-\frac{1}{2}\left(R_{c e}+R_{d}\right) i_{B} \\
V_{C O}=V_{C n}-V_{n O}=V_{C O}^{*}+V_{C O}^{\prime}-\frac{1}{2}\left(R_{c e}+R_{d}\right) i_{C}
\end{array}\right. \\
\left\{\begin{array}{l}
V_{A O}^{\prime}=V^{\prime}\left(2 \operatorname{sign}\left(i_{A}\right)-\operatorname{sign}\left(i_{B}\right)-\operatorname{sign}\left(i_{C}\right)\right) \\
V_{B O}^{\prime}=V^{\prime}\left(2 \operatorname{sign}\left(i_{B}\right)-\operatorname{sign}\left(i_{C}\right)-\operatorname{sign}\left(i_{A}\right)\right) \\
V_{C O}^{\prime}=V^{\prime}\left(2 \operatorname{sign}\left(i_{C}\right)-\operatorname{sign}\left(i_{B}\right)-\operatorname{sign}\left(i_{A}\right)\right)
\end{array}\right. \\
\left\{\begin{array}{l}
V_{A O}^{*} \approx \frac{1}{3} V_{d c} \frac{2 T_{A}-T_{B}-T_{C}}{T_{s}} \\
V_{B O}^{*} \approx \frac{1}{3} V_{d c} \frac{2 T_{B}-T_{A}-T_{C}}{T_{s}} \\
V_{C O}^{*} \approx \frac{1}{3} V_{d c} \frac{2 T_{C}-T_{B}-T_{A}}{T_{s}}
\end{array}\right.
\end{gathered}
$$

Where $\quad V^{\prime}=\frac{1}{6}\left(V_{d c} \frac{2\left(T_{o f f}-T_{o n}-T_{d}\right)}{T}-V_{c e o}-V_{d o}\right) \quad, T_{o n}$ stands for power device turn-on time, $T_{\text {off }}$ stands for power device turn-off time, $T_{d}$ stands for the dead time, $V_{c e^{-}} V_{d}$ is too small to be ignored.

\section{The effect of DTCV and a new voltage}

\section{compensation strategy}

Accurately estimate of the inverter output voltage, we must know the motor phase current direction from equation(20).In this paper, we used the indirect method for determining the direction of the current, which is based on the concept of vector. The direction of the current is according to the angle between current and voltage vector (power factor) to indirectly determine.

The output of the inverter for three-phase current is $i_{A}, i_{B}, i_{C}$, Three phase voltage is $u_{A}, u_{B}, u_{C}$. Firstly, $C L A R K$ transform is applied to three phase current and phase voltage.

$$
\begin{aligned}
& {\left[\begin{array}{l}
i_{s \alpha} \\
i_{s \beta}
\end{array}\right]=\frac{2}{3}\left[\begin{array}{ccc}
1 & -\frac{1}{2} & -\frac{1}{2} \\
0 & \frac{\sqrt{3}}{2} & -\frac{\sqrt{3}}{2}
\end{array}\right]\left[\begin{array}{l}
i_{A} \\
i_{B} \\
i_{C}
\end{array}\right]} \\
& {\left[\begin{array}{l}
u_{s \alpha} \\
u_{s \beta}
\end{array}\right]=\frac{2}{3}\left[\begin{array}{ccc}
1 & -\frac{1}{2} & -\frac{1}{2} \\
0 & \frac{\sqrt{3}}{2} & -\frac{\sqrt{3}}{2}
\end{array}\right]\left[\begin{array}{l}
u_{A} \\
u_{B} \\
u_{C}
\end{array}\right]}
\end{aligned}
$$

Then, two phase currents $i_{s \alpha}$ and $i_{s \beta}$ are transformed into the coordinate system, which is based on the stator voltage vector for the $\mathrm{d}$ axis synchronous rotating coordinates.

$$
\left[\begin{array}{l}
i_{s d} \\
i_{s q}
\end{array}\right]=\left[\begin{array}{cc}
\cos \varphi & \sin \varphi \\
-\sin \varphi & \cos \varphi
\end{array}\right]\left[\begin{array}{c}
i_{s \alpha} \\
i_{s \beta}
\end{array}\right]
$$

Where $\varphi$ is the angle between the vector and the A axis. $\varphi=\arctan \frac{u_{s \beta}}{u_{s \alpha}}$

Power factor angle $\theta$ is the angle between the current and voltage vector, which is obtained by $i_{s d}$ and $i_{s q}$.

$$
\theta=\arctan \frac{i_{s q}}{i_{s d}} \text { 。 }
$$

The relationship between voltage vector and current vector is shown in Fig.3. 
In the actual system, the stator voltage vector angle $\varphi$ is known. Power factor angle $\theta$ can be real time estimation through the instantaneous value of threephase voltage and three-phase current. According to Fig.3,the angle $\theta_{i}$ between the current vector and the $\beta$ axis is expressed as: $\theta_{i}=\varphi-\theta$

Bias voltage compensationis determined by the current direction. However, the three-phase current direction is determined by the current vector angle $\theta_{i}$. The relationship between $\theta_{i}$ and three-phase current direction as shown in Equation 4[10].

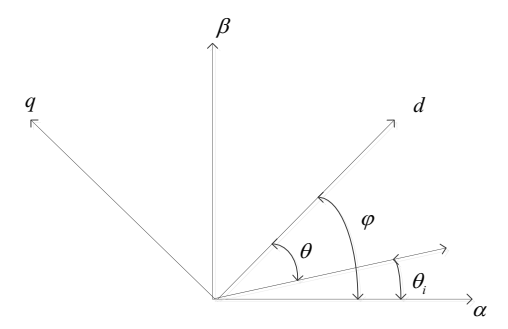

Fig.3 Relationship between voltage and current

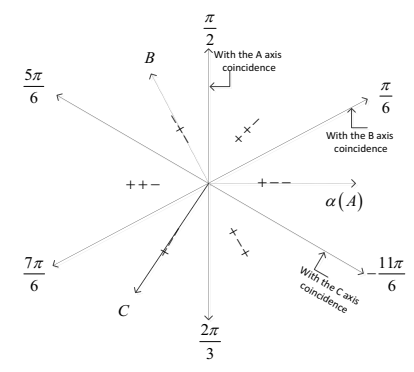

Fig.4 Relationship between ${ }{ }_{i}$ and Three-phase vector current direction

According the above analysis, method is given as follows, which is three phase voltage dead zone compensation.

(1) $A, B, C$ three-phase current direction is determined by $\theta_{i}$ and Fig.4. An angle threshold is introduced to the process and when this angle is less than the threshold value of angle of three-phase voltage compensation, this point of view is the difference between $\theta_{i}$ and boundary point and Boundary point. This can avoid the error estimate of the error caused by the current direction.

(2) According to the current direction and formula (20), we can calculate the voltage error $V_{A O}^{\prime}, V_{B O}^{\prime}, V_{C O}^{\prime}$ caused by the dead time.
(3) The formula (22) and the calculated voltage error can calculate the real value of $A-B$ axis voltage.

$$
\begin{aligned}
& {\left[\begin{array}{l}
\Delta u_{s \alpha} \\
\Delta u_{s \beta}
\end{array}\right]=\frac{2}{3}\left[\begin{array}{ccc}
1 & -\frac{1}{2} & -\frac{1}{2} \\
0 & \frac{\sqrt{3}}{2} & -\frac{\sqrt{3}}{2}
\end{array}\right]\left[\begin{array}{l}
V_{A O}^{\prime} \\
V_{B O}^{\prime} \\
V_{C O}^{\prime}
\end{array}\right]} \\
& \left\{\begin{array}{l}
u_{s \alpha}^{*}=u_{s \alpha}+\Delta u_{s \alpha} \\
u_{s \beta}^{*}=u_{s \beta}+\Delta u_{s \beta}
\end{array}\right.
\end{aligned}
$$

Finally, the formula(23)and type(6)-(8)can be calculated by permanent magnet synchronous wind power generator rotor position and speed.

\section{Experimental Results}

This paper established the hardware platform of the speed sensorless vector control system for $P M S G$ based on TMS320F28335 control board.Fig.5 shows the control block diagram and Fig.6 shows motor control and test platform.

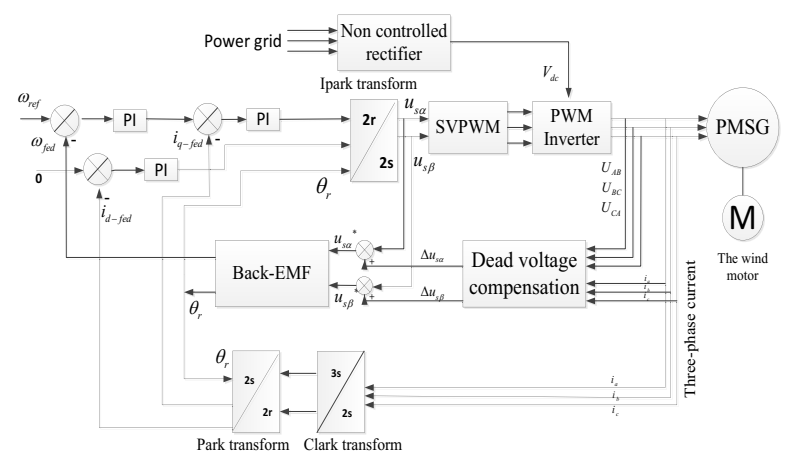

Fig.5 Consider the impact of dead zone sensorless PMSG

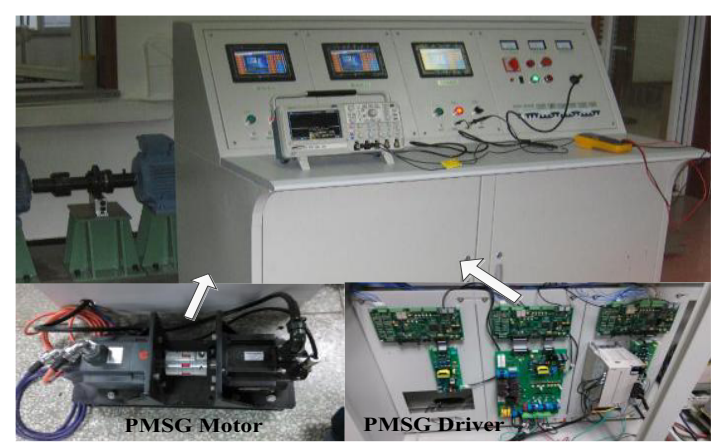

Fig.6 The actual PMSG test platform control system block diagram

In order to verify the validity of this control method, the following experiments were studied. $P M S G$ driver is composed by four functional blocks: Rectifier module, IPM module, DSP module, and interface 
circuit. The controller is based on DSP TMS320F28335 produced by Texas Instument. The type of IPM module in the inverter is PM75RL1A120.The main spectifications of $P M S G$ and control parameters in the experiment are given in Table 1.

Tab.1 Specifications of tested PMSG and control parameters

\begin{tabular}{|c|c|}
\hline Item & Value \\
\hline Rated Speed & $1200 \mathrm{r} / \mathrm{min}$ \\
\hline Rated Power & $0.88 \mathrm{Kw}$ \\
\hline Rated Torque & $4.5 \mathrm{Nm}$ \\
\hline Rated voltage & $160 \mathrm{~V}$ \\
\hline Rated current & $5.5 \mathrm{~A}$ \\
\hline Rs & $2.875 \Omega$ \\
\hline Ls & $0.0085 \mathrm{mH}$ \\
\hline P & 3 \\
\hline Ts & $0.0004 \mathrm{~s}$ \\
\hline ton & $1 \mathrm{us}$ \\
\hline toff & $1 \mathrm{us}$ \\
\hline td & $6.4 \mathrm{us}$ \\
\hline Vs & $2 \mathrm{~V}$ \\
\hline
\end{tabular}

When the motor is at low speed, the impact of deadtime effect is very clear. In order to verify the effect of the dead-time compensation, the reference speed is 80r/min, The test result is shown in Fig.6.

Fig.7. shows a comparison of rotor position of waveform before and after the dead voltage compensation, when the motor is in low speed (30r/min). We can see that the estimation of the rotor position has obvious distortion in Fig.7.a and the position of the rotor without waveform distortion in Fig.7.b.Fig. 8 is the voltage waveform before and after compensation, when the motor is in $50 \mathrm{r} / \mathrm{min}$.

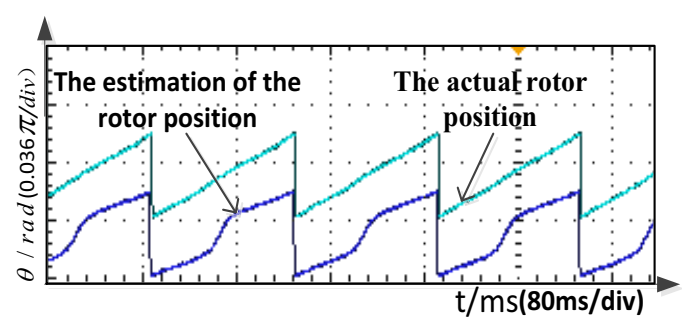

(a)Before compensation

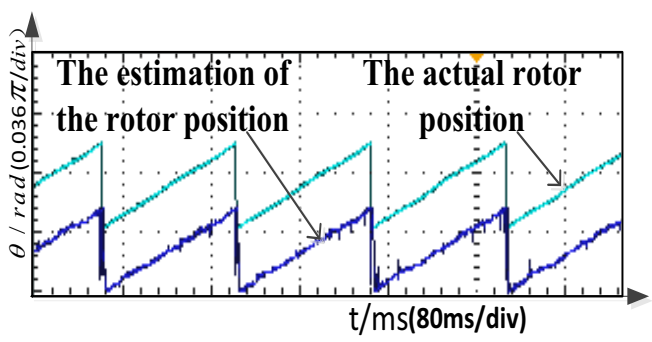

(b)After compensation

Fig.7 Comparing the actual rotor position and the estimated rotor position when motor $30 \mathrm{r} / \mathrm{min}$

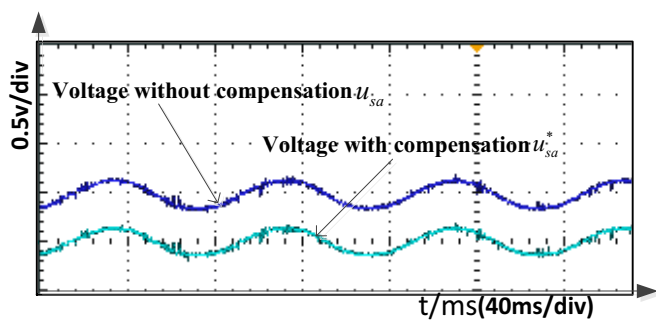

Fig.8 After correction waveforms when motor 50r / min

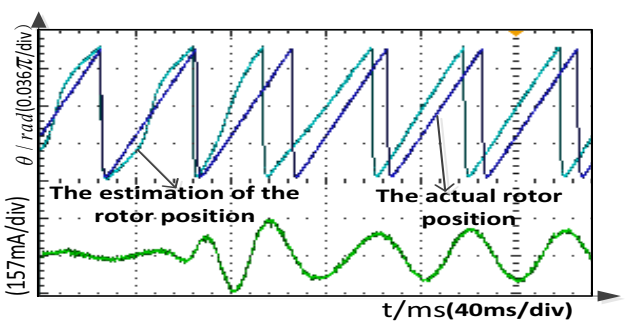

(a)Before compensation 


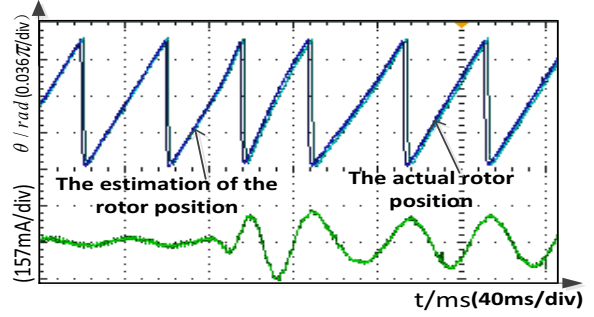

(b)After compensation

Fig.9 Rotor position and current waveforms when the load motor $50 \mathrm{r} / \mathrm{min}$

Fig.9.shows a comparison of rotor position of waveform and current waveform before and after the Dead-time voltage compensation, when the load motor is in low speed(50rpm). The rotor position estimation value had great phase deviation before dead time compensation, but after the compensation and under light load condition, the motor still run well all the time. System recovery time is about $200 \mathrm{~ms}$, the estimation of the rotor position is accurate and the current waveform is good.

\section{Conclusions}

The output voltage of the inverter model is established according to the permanent magnet synchronous generator system. Based on the compensation of voltage, sampling current and BackEMF algorithm, a novel Dead-time voltage compensation method is proposed. The experimental results is reasonable. Although the $\mathrm{B} a c k-E M F$ method can estimate the rotor position of the motor, but the estimation accuracy has a strong dependence on the parameters of the motor and the motor speed. When the system is subjected to the dead voltage, the rotor position estimation is very easy to deviate from the actual position and make the system unstable. The control algorithm can effectively improve the stability of the PMSG speed sensorless control system and the estimation accuracy of rotor position. Especially, in the low speed region for $P M S G$, the control precision is better. But when the load of the motor increases, the control method needs to be improved.

\section{Acknowledgements}

This project is sponsored by the National Natural Science Fund(Project Number:51207003).I greatly acknowledge this support.

\section{References}

1. Chinchilla M, Arnaltes S, Burgos J C, et al(2006).Control of permanent-magnet generators applied to variable speed wind-energy systems connected to the grid[J].IEEE Transactions on Energy Conversion,21(1):130-135.

2. Zhao Rende,Wang Yongjun,Zhang Jiasheng(2009).Maximum power point tracking control of the wind energy generation system with direct-driven permanent synchronous generators[J].Proceedings of the CSEE, 29(27):106-111.

3. J.S.Thongam,M.Tarbouchi,e $\operatorname{tal}(2012)$.An Optimium Speed MPPT Controller for Variable Speed PMSG Wind Energy Conversion Systems,38th Annual Conference on IEEE Industrial Electronic Society,4293-4297.

4. Alfio Consoli, Giuseppe Scarcella, Antonio Testa(2001).Industry application of zero-speed sensorless control techniques for PM asynchronous motors. IEEE Trans. Ind.Appl. 37(2):13-521.

5. Sergeant P,Dupre L, et al(2010).Losses in Sensorless Controlled Permanent Magnet Synchronous Machines[J].IEEE Transaction on Magnetics , 46(2):590593.

6. W.Qiao,W.Zhou,J.M.Aller,and R.G.Harley(2008).Wind speed estimation based sensorless output maximization control for a wind turbine driving a DFIG, IEEE Trans. Power Electronics, vol. 23, no.3,1156-1169.

7. Tong Li,Zou Xudong,Feng Shushuai,etal(2013).A sensorless control scheme for permanent magnet synchronous generators using predictive dead-beat algorithm[J].Transactions of China Electrotechnical Society,28(3):17-26.

8. Li Zhengxi,Yang Liyong(2013).AC and DC speed control system[M].Beijing: Publishing House of Electronics Industry,2:261-268.

9. Yang Li-yong,Chen Zhigang,Chen Weiqi.(2012).Out Voltage Model of VSI-Inverter and a Novel DeadTime 


\section{MATEC Web of Conferences}

CompensationMethod[J].Transactions of China Electrotechnical Society,27(1):183-185.

10. Kan Lin and Z.Q.Zhu(2014).Online Estimation of the Rotor Flux Linkage and Votage-Source Inverter Nonlinearity in Permanent Magnet Synchronous Machine Drives $[\mathrm{J}]$. IEEE Tansactions on Industrial Electronica, 29(1):419-421. 